\title{
Existential therapy versus acceptance and commitment therapy for feelings of loneliness and irrational beliefs in male prisoners
}

\author{
Abolfazl Ziaee (1), Hamid Nejat (1), Hossein Akbari Amarghan (2), Elham Fariborzi (1) \\ (1) Department of Educational Sciences, Mashhad Branch, Islamic Azad University, Mashhad, \\ Iran; (2) Department of Psychology, Quchan Branch, Islamic Azad University, Quchan, Iran. \\ This article is distributed under the terms of the Creative Commons Attribution Noncommercial License (CC BY-NC 4.0) which permits \\ any noncommercial use, distribution, and reproduction in any medium, provided the original author(s) and source are credited.
}

\begin{abstract}
Today's people live in a society with many dangers to their peace and security. The effectiveness of different therapies in psychological variables needs to be evaluated to reach the most precise therapies based on research evidence. This study aimed to compare the effectiveness of existential therapy (ET) and acceptance and commitment therapy (ACT) in alleviating the loneliness and irrational beliefs of male prisoners. In the present quasi-experimental study, the statistical population consisted of all married male prisoners aged between 25 to 45 years in Mashhad Central Prison in the first half of 2017. Among the statistical population, 36 people were selected and then randomly placed in three research groups. The two experimental groups underwent eight separate intervention sessions, ET, and ACT. At the beginning and end of the study, all of the three groups were evaluated by a research questionnaire, including the loneliness scale. The results of data analysis showed that, in comparison with the control group, the changes in the other two groups under ET and ACT were significant as to the feeling of loneliness and irrational beliefs of prisoners. However, there was no significant difference between the effects of these two treatments. The present research was limited in the case of examining the followup stage due to lack of access and cooperation of the subjects, incorporating some control variables (such as the history of substance use and psychiatry), and employing other evaluation methods (e.g., interview). It is highly suggested that future research should address these limitations.
\end{abstract}

Key Words: Feelings of loneliness; irrational beliefs; acceptance and commitment therapy; existential therapy; prisoners.

Eur J Transl Myol 32 (1): 10271, 2022 doi: 10.4081/ejtm.2022.10271

Today, society poses many dangers (e.g., crime) to people's peace and security. Every day, there are disturbing news and reports about various crimes that lead to death, disability, and other physical injuries in society. Crimes are committed for different reasons such as unemployment, low level of education, family and marital problems, crime-triggering social network, substance/alcohol use, poor social functions, anti-social attitudes, personal and emotional factors, and personality and psychological disorders. ${ }^{1}$ Living space plays an important role in human physical and psychological health. Any restrictions on various aspects of this space can increase vulnerability. The term "prison" is associated with difficult conditions for most people, interpreted as a scary, dark, and terrifying environment, which is not far from reality. The prison environment has unique conditions and characteristics; in general, prison is one of the most stressful places for any human being. ${ }^{2,3}$
The study of various psychological and behavioral components of prisoners is one of the main topics of interest to psychologists and social science experts. Surveys show that more than 10.1 million people worldwide and 220,000 people in Iran are in prison, highlighting the importance of investigating their physical and psychological health. ${ }^{4,5}$ Research in prisons has shown that physical and psychological disorders are more prevalent in prisoners than in the general population. At least half of these people have personality disorders, one million of them suffer from severe psychiatric disorders such as mood disorders, posttraumatic stress disorder, or psychosis, and almost all of them experience adjustment disorders due to continuous stress conditions, especially in the presence of secondary alexithymia. ${ }^{6-8}$ Several thousand prisoners around the world commit suicide annually; $89 \%$ of them have symptoms of depression, and $74 \%$ have physical symptoms of stress, which is higher compared to the 
general population. ${ }^{2,9,10}$ Further, research has shown that incarceration has a negative effect on prisoners, especially young people, forcing them to leave their family, jobs, and social life and increasing the inclination to commit a crime in prison. ${ }^{11}$ Feeling alone is experienced by prisoners due to their psychological condition and the specific environment of prison, which needs to be studied. Since human beings are born and live in communities, they are always involved in communication issues, such as loneliness as an integral part of social life. It has been said that interpersonal anomalies are rooted in loneliness. In general, loneliness can be divided into intrapersonal, interpersonal, and existential categories. ${ }^{12}$ Intrapersonal loneliness is the personality part that feels lonely, synonymous with a state of loneliness or social isolation. However, existential loneliness is a situation related to human existence, which is not related to separation from others or lack of intimate relationships. ${ }^{13}$ Instead, it implies that man is permanently incapable of understanding how others perceive the world. Irrespective of his connection with others, he is still alone in his existence; in other words, he has entered this world alone and will leave it alone. ${ }^{14}$ This loneliness is traced back to the distance between oneself and others. In fact, existential loneliness is a component of the existential approach. ${ }^{12-14}$ One of the three areas studied by psychologists on the human psyche is the field of cognition, thinking, and interpretation. Irrational beliefs can probably be assumed as predictors of psychological functioning in prisoners. According to the rational-emotional-behavioral theory (REBT), the core thought in the logical and irrational processes in human behavior is that man has several basic desires, goals, and preferences as their main thinking components. More to the point, human beings live better and more effectively when they have a sense of selfefficacy or dominance (self-satisfaction), succeed in setting goals (goal and satisfaction), are approved or less disapproved by people who are important to them (love and approval), and stay healthy (health satisfaction). ${ }^{15}$ Irrational beliefs are inappropriate solutions used by a person to their problems, which occur in their minds and affect their lives. Recent analyses have suggested that the social and cultural environment of the individual is the basis of irrational beliefs. In other words, the individual's mental framework is shaped by information received from the environment. Further, irrational beliefs trigger many dysfunctional behaviors and many failures. ${ }^{15}$ Accordingly, interventions and treatment programs are needed to enhance the psychological state of prisoners. In this regard, various therapies have been studied, such as existential therapy (ET) as one of the psychological approaches to improving the psychological condition of prisoners. This theory has a philosophical nature and is a set of ideas and theories about human beings, called existential psychotherapies. ${ }^{16}$ The existential approach in psychology as a common situation for all people, regardless of culture, religion, ethnicity, and race, deals with deep and central issues such as loneliness, meaninglessness, death, and freedom. ${ }^{17}$ This approach encourages clients to face those aspects of their lives that they have always avoided, courageously acknowledge these unfortunate events, and accept that happiness and joy are met provided that one can realize the temporary nature of security and vitality in life. ${ }^{15}$ Existential psychotherapy focuses on the importance of human life based on his perspective on life. Existential psychotherapy is an attitude to life issues such as life and

Table 1. Summary of group existential psychotherapy sessions

\begin{tabular}{ll}
\hline Sessions & Content of sessions \\
\hline First session & $\begin{array}{l}\text { Admission and welcome, explaining the aims, acquaintanceship among } \\
\text { members, describing how the group function, conducting the pre-test }\end{array}$ \\
Second session & $\begin{array}{l}\text { Explaining the concept of self-consciousness and existential anxiety } \\
\text { Third session }\end{array}$ \\
$\begin{array}{l}\text { Going over the previous session practices, member's expressions and } \\
\text { feedbacks about the experience of loss, and finally teaching death anxiety to } \\
\text { be accepted }\end{array}$ \\
$\begin{array}{l}\text { Fourth session } \\
\text { Fifth session }\end{array}$ \\
$\begin{array}{l}\text { Exaluating and explaining the concept of loneliness } \\
\text { Seventh session }\end{array}$ \\
$\begin{array}{l}\text { Describing the purpose, responsibility, and freedom in life } \\
\text { Assessing strategies for giving meaning to life and coping with the emptiness } \\
\text { of life } \\
\text { Summarizing previous material and finding the relation between self- } \\
\text { awareness, loneliness, death, purposefulness, and meaning in life and coping } \\
\text { with children's illnesses, as well as post-test implementation }\end{array}$
\end{tabular}


Table 2. Summary of acceptance and commitment therapy sessions

\begin{tabular}{ll}
\hline Sessions & Content of sessions \\
\hline First session & $\begin{array}{l}\text { Establishing a therapeutic relationship, acquainting people with the research } \\
\text { topic, answering the questionnaire, and making a treatment contract }\end{array}$ \\
Second session & $\begin{array}{l}\text { Discovering and investigating treatment methods and evaluating their } \\
\text { effectiveness, discussing the temporary and ineffectiveness of treatments }\end{array}$ \\
& using allegory, receiving feedback, and giving assignments \\
Third session & Assisting clients in identifying ineffective control strategies and realizing their \\
& futility, accepting painful personal events without further conflict using \\
& allegory, receiving feedback, and giving assignments \\
Fourth session & $\begin{array}{l}\text { Explanation about avoiding painful experiences and being aware of their } \\
\text { consequences, teaching acceptance steps, changing language concepts using } \\
\text { Fifth session }\end{array}$ \\
allegory, teaching relaxation, receiving feedback, and giving assignments \\
Introducing a three-dimensional behavioral model to express the common \\
relationship between behavior/emotions, psychological functions, and \\
observable behavior, as well as discussing attempts to change behavior based \\
on the developed model, receiving feedback, and giving assignments \\
Explaining the concepts of role and context, observing oneself as a context \\
and making contact with oneself using allegory, being aware of different \\
sensory perceptions, and separating the senses that are part of the mental \\
content; receiving feedback, and giving assignments \\
Explaining the concept of values, encouraging change, empowering clients \\
for a better life, practicing focus, receiving feedback, and giving assignments \\
Teaching commitment to action and identifying behavioral plans as per \\
values, summarizing sessions, conducting post-tests \\
Eighth session
\end{tabular}

death, freedom, responsibility for oneself and others, meaning in life, and the concept of meaninglessness. This therapeutic approach, superior to any other approach, examines man's self-awareness and ability to look beyond their problems and existential issues. In this approach, no attempt is made to eliminate human suffering because human life is inherently painful. Instead, human beings are helped to find meaning in life by accepting the reality of pain and suffering, whereby pain will be enjoyable. ${ }^{16}$ The advantage of existential psychotherapy over other approaches is its focus on available choices and paths to personal growth. It also leads to accepting personal responsibilities, expanding awareness of current situations, and a sense of commitment to decision-making and action. This approach seeks to help people realize that although they may not be able to change some of the unpleasant and painful aspects of their lives, they can understand how these events are perceived and react to them. ${ }^{12}$ Another practical treatment approach to improving prisoners' mental health is Acceptance and Commitment Therapy (ACT). This therapeutic approach is one of the new and effective therapies for solving psychological problems and disorders. ${ }^{18}$ Its basic principles include (i) Accepting or wanting to experience pain or other disturbing events without trying to control them; (ii) Acting based on value or commitment, with a desire to act towards meaningful personal goals before eliminating unwanted experiences. ${ }^{19}$ As an essential part of the psychotherapy in ACT, the patient must be guided through the path of action to reach the values expressed by them. ${ }^{20}$ Attempts to change behavior for better adaptation have led to psychological barriers addressed through the ACT process. Researchers have paid less attention to ACT that is one of the third wave therapies. ${ }^{18-20}$ In a committed activity, the individual is encouraged to do their best to achieve the goal. In other words, in this type of treatment, the main aim is to create psychological flexibility, i.e., making practical choices among different most appropriate options rather than avoiding disturbing thoughts, feelings, memories, and desires. Empirical evidence for the effectiveness of this treatment in disorders such as depression, psychosis, social phobia, and high-risk behaviors such as alcohol and substance use has been identified. ${ }^{21}$ Prisoners, on a larger scale, reflect some of society's values. They are still part of human society, regardless of the type of crime/penalty they have been arrested for/sentenced to. Most prisoners suffer from mental disorders, either rooted in physical problems or triggered by the individual's family and mental environment. In both cases, there is a need for counseling and psychotherapy for all prisoners. On the 
Table 3. Descriptive variables of this study for the three under-test groups at pre-test and post-test levels

\begin{tabular}{lllll}
\hline Variables & Categories & ET group & ACT group & Control group \\
\hline \multirow{2}{*}{$\begin{array}{l}\text { Feeling of } \\
\text { loneliness }\end{array}$} & Isolation & M (SD) & M (SD) & M (SD) \\
\cline { 2 - 4 } & Being social & $19.31(3.42)$ & $19.30(3.19)$ & $27.90(3.43)$ \\
& Lack of intimate friendship & $17.77(3.56)$ & $15.44(4.24)$ & $11.53(5.33)$ \\
& Not feeling lonely & $20.65(3.66)$ & $14.10(3.15)$ & $17.46(4.16)$ \\
& Total score & $16.46(2.09)$ & $14.75(3.24)$ & $12.2(3.19)$ \\
Irrational & Helplessness against change & $74.67(5.66)$ & $62.65(5.45)$ & $69.78(7.45)$ \\
beliefs & & $34.22(4.15)$ & $40.89(3.03)$ & $37.13(3.78)$ \\
& & & & \\
& Expecting approval from others & $38.09(3.08)$ & $35.75(4.14)$ & $41.09(4.54)$ \\
& Avoiding the problem & $41.19(5.24)$ & $37.11(3.33)$ & $34.68(3.33)$ \\
& Emotional irresponsibility & $33.42(2.67)$ & $33.40(5.53)$ & $38.65(5.43)$ \\
& Total score & $148.56(3.54)$ & $146.46(9.35)$ & $153.46(10.31)$
\end{tabular}

Note. ACT: Acceptance and commitment therapy; ET: Existential therapy; M: Mean; SD: Standard deviation.

other hand, it is necessary to study the effectiveness of different therapies in the psychological variables of this group in order to create practical treatments based on research evidence. Therefore, the present study aims to compare the effectiveness of ET and ACT in male prisoners' loneliness and their irrational beliefs.

\section{Materials and Methods}

\section{Participants and procedure}

This research is a quasi-experimental trial, conducted as pre-test/post-test, with a control group and two experimental groups. The statistical population of the study included all married male prisoners aged between 25 to 45 years in Mashhad Central Prison, who were sentenced to more than one year in prison and had passed counseling courses and basic psychological classes in the counseling unit. The study was approved by the ethics committee of the Islamic Azad University, Mashhad Branch (IR.IAU.MSHD.REC.1399.131), and all procedures were in accordance with the latest version of the Declaration of Helsinki. Prior to participation, written informed consent was obtained from all participants and their parents/legal guardians after a comprehensive explanation of the study procedures.

Exclusion criteria were:

(i) intellectual disability;

(ii) a history of serious neurological disorders;

(iii) hearing loss.

The sample of the present study consisted of 36 prisoners who were selected by the purposive sampling method and randomly divided into two experimental groups (12 people in each group) and a control group (12 people). The experimental groups underwent eight sessions of intervention. The data were analyzed by SPSS software using multivariate analysis of covariance (MANCOVA).

\section{Instruments}

Questionnaires and materials used in this study were as follows:

\section{UCLA Loneliness Scale}

The UCLA Loneliness Scale has 20 questions scored on the 5-point Likert scale, i.e., never (score 1), rarely (score 2 ), sometimes (score 3 ), often (score 4), and always (score 5). Questions 19, 16, 15, 10, 9, 6, 5, 1 and 20 are scored reversely. The test scores range from 20 to 200, where a higher score indicates a more intense sense of loneliness. ${ }^{22}$ Russell and Ferguson first developed the Russell Loneliness Scale, followed by three revisions. The final version of the scale was used among four groups of students, nurses, teachers, and the elderly through various means such as self-report and interview. Their Cronbach's alpha coefficient ranged from 0.89 to 0.94 , which was satisfactory. ${ }^{23}$ Sodani et al. ${ }^{24}$ studied the psychometric properties of the Persian version of the UCLA Loneliness Scale and obtained the reliability coefficient of Cronbach's alpha method equal to 0.81 .

Four-Factor Irrational Beliefs Test-Ahvaz (4IBT-A)

The 4IBT-A was developed by Motamedin et al. ${ }^{25}$ based on the 10-item Jones Irrational Beliefs Test by factor analysis in Iranian society. It consists of 40 questions scored on the 5-score Likert scale, ranging from one (strongly disagree) to five (strongly agree).

Motamedin et al. ${ }^{25}$ also used Cronbach's alpha method and estimated the reliability of the test for helplessness with change, demand for approval, problem avoidance, emotional irresponsibility, and the total test at $0.77,0.68$, $0.59,0.68$, and 0.86 , respectively.

\section{The treatment process program}

The treatment process program in the two experimental groups is presented in Table 1 and Table 2. 
Existential, acceptance and commitment therapies in male prisoners

Eur J Transl Myol 32 (1): 10271, 2022 doi: 10.4081/ejtm.2022.102171

\begin{tabular}{llllll}
\hline \multicolumn{7}{c}{ Table 4. Statistics } & \multicolumn{6}{l}{ for the normality of data distribution } \\
\hline Variables & Group & Tilt & Elongation & Shapiro-Wilk & p-value \\
\hline Feeling of loneliness & ET & -0.6 & 1.5 & 0.703 & 0.254 \\
& ACT & 1.6 & 1.3 & 0.817 & 0.03 \\
& Control & 0.9 & 0.9 & 0.768 & 0.769 \\
Irrational beliefs & ET & 0.8 & 1.6 & 0.879 & 0.398 \\
& ACT & 1.4 & 1.7 & 0.657 & 0.413 \\
& Control & 0.5 & 0.4 & 0.989 & 0.467 \\
\hline
\end{tabular}

Note. ACT: Acceptance and commitment therapy; ET: Existential therapy.

\section{Results}

Table 3 presents the descriptive variables of this study for the three test groups. Before analyzing the covariance, we investigated the assumptions of this test. The normality of data distribution is presented in Table 4. It is necessary to investigate the normality of data distribution, homogeneity of variance, independence, and assumption of homogeneity of regression slopes to examine the assumptions of analysis of covariance. As can be seen, the variance of the feeling of loneliness in the pre-test and post-test of all three groups ranged from -2 to +2 . Shapiro-Wilk test showed that the loneliness variable is normal in all groups. ${ }^{26}$ According to the significance level of the Levene's test $(F=4.2, p<0.05)$, the assumption of homogeneity of variances was rejected (Table 5). However, since the groups were the same size, they were resistant to the former violation, and parametric analyses could be performed. ${ }^{26}$ For all research variables, the value of test statistics of interaction between pre-test and post-test groups was statistically significant $(p<0.01)$, and the condition of regression slope balance for analysis of covariance was also established (Table 6). Test results of betweensubject effects also showed that, after adjusting the effects of the pre-test, the $\mathrm{F}$ value of the group became significant $(F=45.24 ; p<0.001) ;(F=29.42 ; p<0.001)$. As can be seen, the difference in the mean score of loneliness and irrational beliefs of the subjects between the control group and both ACT and ET groups was significant $(\mathrm{p}<0.001)$ (Table 7). Therefore, it can be said that ET and ACT had a considerably positive effect on loneliness and irrational beliefs. Also, there was a negligible difference between the ET and ACT groups. In other words, ET and ACT could affect the feeling of loneliness and irrational beliefs of the subjects to the same extent.

\section{Discussion}

The results of data analysis showed that, compared to the control group, the effects of ET and ACT were significant on the variables of loneliness and irrational beliefs (almost no difference between the two latter therapies). These findings were consistent with the results of previous studies. ${ }^{27-32}$ According to Hayes and Strosahl, ${ }^{33}$ as a person enters the ACT process, their involvement in negative mental-verbal processes focusing on themselves and others improves and changes gradually. In the ACT, healing can be well enhanced through avoiding anxiety and worry, freeing oneself from the past and bitter experiences, living in the present, and emphasizing values and committed action to reduce stress. Also, the underlying idea of ACT is to accept what is beyond our control and will. ${ }^{34}$ In therapeutic processes based on acceptance and commitment, it is very likely that a person pursues committed and value-oriented actions in different areas simultaneously. ${ }^{35}$ ACT can help a person experience

Table 5. Investigation of independence and homogeneity of regression slopes assumption (dependent variables: loneliness and irrational beliefs)

\begin{tabular}{lllllll}
\hline Variables & Source of change & Total squares & df & Mean Squares & F & P-value \\
\hline Feeling of loneliness & Pre-test & 73.55 & 1 & 37.02 & 41.1 & $<0.001$ \\
& Group interaction $\times$ & 41.65 & 2 & 27.34 & 0.34 & 0.659 \\
& Pre-test & & & & & \\
& Error & & 884.9 & 30 & 29.5 & \\
Irrational beliefs & Pre-test & 109.35 & 1 & 54.76 & 33.14 & $<0.001$ \\
& Group interaction $\times \quad 41.13$ & 2 & 31.35 & 0.33 & 0.176 \\
& Pre-test & & & & &
\end{tabular}

Note. df: Degree of freedom. 
Existential, acceptance and commitment therapies in male prisoners

Eur J Transl Myol 32 (1): 10271, 2022 doi: 10.4081/ejtm.2022.102171

\begin{tabular}{|c|c|c|c|c|c|c|c|}
\hline Variables & $\begin{array}{l}\begin{array}{l}\text { Source } \\
\text { change }\end{array} \\
\end{array}$ & of Total squares & $\mathrm{df}$ & Mean squares & $\bar{F}$ & P-value & Squares \\
\hline \multirow[t]{3}{*}{ Feeling of loneliness } & Pre-test & 1768.52 & 1 & 1768.52 & 43.89 & $<0.001$ & 0.354 \\
\hline & Group & 2580.16 & 2 & 1290.08 & 45.24 & $<0.001$ & 0.415 \\
\hline & Error & 768.56 & 32 & 35.11 & & & \\
\hline \multirow[t]{3}{*}{ Irrational beliefs } & Pre-test & 17689.984 & 1 & 17689.984 & 31.42 & $<0.001$ & 0.312 \\
\hline & Group & 2567.246 & 2 & 1251.357 & 29.42 & $<0.001$ & 0.287 \\
\hline & Error & 2415.536 & 32 & 34.14 & & & \\
\hline
\end{tabular}

less stress by increasing self-awareness and self-control and prevent stress by acceptance training. In this therapy, individuals are taught to respond to problems and issues with greater acceptance, non-judgment, lack of intellectual conflict, and cognitive-behavioral flexibility. Further, ACT allows individuals to change relationships with their inner experiences in the first place, reduce empirical avoidance, increase flexibility, and rise worthy actions. Changing relationships with inner experiences involves expanding and clarifying inner consciousness. In addition, it emphasizes the strengthening of a non-judgmental and compassionate relationship with experiences. Self-correction (a concept that contradicts the judgment and criticism most authorities have of their thoughts and feelings) is an important aspect of this treatment to reduce reactivity, fear, and misplaced judgments. Finally, the goal of this treatment is to experience thoughts, feelings, and emotions as they occur naturally. ${ }^{33}$ Moreover, ET and feeling of loneliness have many theoretical commonalities, especially in terms of awareness, responsibility, choice, and decision making. One of the characteristics of feeling lonely is having no purpose and meaning in life, leading to low self-esteem.
Logotherapy has been able to reduce feelings of loneliness by helping subjects to discover their true self, choose personal values, and find meaning in their lives. $^{24}$ One of the elements of high self-esteem is to have valuable goals and strive to achieve them. Since the most important goal of the subjects selected during ET is to achieve meaning, acceptance, and responsibility, they can increase self-esteem effectively. In fact, a person facing life problems with acceptance, responsibility, and meaning can acquire feelings and thoughts such as belonging, planning, ability to influence, problem-solving, and effort. ${ }^{36}$ One of the characteristics of people with irrational beliefs is the cognitive fusion that happens when a person thinks their thoughts are always correct. In fact, many problems arise from focusing on the texture of depressive thoughts. ${ }^{37}$ Therefore, we addressed the thoughts and feelings that led to undesirable behaviors of the subjects, which reduced their credibility and flexibility. Thus, metaphors, exercises, contradictions, and language conventions of ACT were used in this context to describe that the mind cannot have all the answers and distinguish between itself and its thoughts. Cognitive disruption skills worked on judgments, interpretations,

Table 7. Pair comparison of subjects' feeling of loneliness and irrational beliefs in three groups.

\begin{tabular}{|c|c|c|c|c|c|}
\hline Variables & Group i & Group j & Mean differentiation & SD & p-value \\
\hline \multirow[t]{6}{*}{ Feeling of loneliness } & Control & ACT & 16.64 & 2.171 & $<0.001$ \\
\hline & & ET & 13.53 & 2.181 & $<0.001$ \\
\hline & $\mathrm{ACT}$ & Control & -16.64 & 2.171 & $<0.001$ \\
\hline & & ET & -1.51 & 2.167 & 0.314 \\
\hline & ET & Control & -13.53 & 2.181 & $<0.001$ \\
\hline & & $\mathrm{ACT}$ & 1.51 & 2.167 & 0.314 \\
\hline \multirow[t]{6}{*}{ Irrational beliefs } & Control & ACT & 8 & 1.312 & $<0.001$ \\
\hline & & ET & 5.10 & 1.567 & $<0.001$ \\
\hline & $\mathrm{ACT}$ & Control & -8.10 & 1.415 & $<0.001$ \\
\hline & & ET & -2.10 & 2.979 & 0.231 \\
\hline & ET & Control & -5.10 & 2.536 & $<0.001$ \\
\hline & & ACT & 2.10 & 1.417 & 0.231 \\
\hline
\end{tabular}

Note. ACT: Acceptance and commitment therapy; ET: Existential therapy; SD: Standard deviation. 
and predictions. In fact, the hidden function of language was revealed to the subjects, and the authorities were instructed to separate themselves from thoughts, emotions, and feelings. Ruminants and repetitive thought patterns are characteristics of depressed people, which put them out of touch with the present moment and take them into a negative past or future. Despite that a depressed person may want to have a warm relationship, they do not go out and meet people because they may constantly think about how people have mistreated them in the past. Although rumination seems to be more focused on the past, the high rate of concurrence of depression and anxiety disorders indicates that depressed clients are often preoccupied with the future. ${ }^{38}$ As one of the dimensions of ACT, being in the present was emphasized in therapy sessions, whereby the subjects could realize their depressive thoughts. In this regard, meditation was used to enable them to return to the present moment and separate from rumination and, in turn, they were able to get a feeling of changeability and reduce irrational beliefs. The existential approach implies that mortality and transience are not only the main features of life but also key factors in its meaning. Following the group process, the individual becomes aware that although they cannot change the real conditions of life, they can vary coping ways from despair and fruitlessness -one of the components of lack of mental health — to the flourishing and excellence of individuality by giving meaning to how the self is. People face new challenges related to independence, education, social communication, and issues imposed by a new environment in the absence of family. These changes may lead to increased stress, prevalence of adaptation problems, decreased mental health, and reduced overall performance. Throughout the process, the group members identify and explore these issues, concerns, values, and perspectives on themselves and their lives to be changed so as to provide creative attitudes, worldviews, and values appropriate to their situation. Therefore, the most prominent feature of this approach is the emphasis on the therapeutic relationship and its role in bringing about a change in clients. ${ }^{15,16}$

Limitations of the research were related to examining the follow-up stage of the subjects due to lack of access and cooperation of the subjects, examining and controlling variables such as a history of substance use and psychiatry, and investigating other evaluation methods such as interview. It is suggested that they should be addressed in future research. The results of data analysis showed that the effects of ET and ACT were similarly significant on the variables of loneliness and irrational beliefs. Indeed, humans are born with the need for communication and intimacy, and feelings of isolation and loneliness can be the main focus of many disorders, especially for prisoners, which can be related to irrational beliefs. Based on ET, prisoners in these situations can find meaning in life, choose their reactions freely to the situations ahead, and responsibly accept the consequences of their actions and choices. On the other hand, they realize that problems are inevitable and there is only one opportunity left in this situation, i.e., changing their attitude and approach towards the problem, enduring the suffering, and spending their time on improving the quality of life due to the transient nature of life. These changes can give them new insights and also affect their irrational beliefs and feelings of loneliness. ACT helps prisoners define more valuable goals in their lives and put their energy into more transcendent activities. Changing relationships with inner experiences involves expanding and clarifying inner consciousness, which can ultimately lead to the development of external relationships, reduce irrational beliefs, and free one from loneliness.

\section{List of acronyms}

ACT - Acceptance and Commitment Therapy

ET - Existential Therapy

4IBT-A - Four-Factor Irrational Beliefs Test-Ahvaz

\section{Contributions of Authors}

All authors participated in idea formation, data gathering, data analysis and interpretation, manuscript drafting and revising. All contributors approved the manuscript and agreed with study publication.

\section{Acknowledgments}

The authors hereby thank the patients, who aided in conducting the present study.

\section{Funding}

The authors received no specific funding for this work.

\section{Conflict of Interest}

The authors declare no conflict of interests.

\section{Ethical Publication Statement}

We confirm that we have read the Journal's position on issues involved in ethical publication and affirm that this report is consistent with those guidelines.

\section{Corresponding Author}

Hamid Nejat, Assistant Professor, Department of Educational Sciences, Mashhad Branch, Islamic Azad University, Postal Code: 9187147578, Mashhad, Iran. Tel: +98-5136630781, Fax: +98-5136630781.

ORCID iD: ORCID iD: 0000-0003-1380-8802

Email: hamidnejat54@yahoo.com

E-mails and ORCID iD of co-authors

Abolfazl Ziaee: abolfazlziaee@yahoo.com

ORCID iD: 0000-0002-3532-3817

Hossein Akbari Amarghan: hosseinakbariaghdam@yahoo.com

ORCID iD: 0000-0002-1761-8945

Elham Fariborzi: elham.fariborzi@yahoo.com

ORCID iD: 0000-0002-1378-3513 


\section{References}

1. Weller, MP, Weller, B. Crime and psychopathology. Br Med J (Clin Res Ed). 1986 Jan 4;292(6512):55-6. doi: 10.1136/bmj.292.6512.55.

2. Konrad, N, Welke, J, Opitz-Welke, A. Prison psychiatry. Curr Opin Psychiatry. 2012 Sep;25(5):375-80. doi: 10.1097/YCO.0b013e $328356 b 7 c 3$.

3. Baybutt, M, Dooris, M, Farrier, A. Growing health in UK prison settings. Health Promot Int. 2019 Aug 1;34(4):792-802. doi: 10.1093/heapro/day037.

4. Gee, J, Loewenthal, D, Cayne, J. Psychotherapy and despair in the prison setting. Int J Prison Health. 2015;11(3):141-56. doi: 10.1108/IJPH-11-20140042.

5. Kristofersson, GK, Kaas, MJ. Stress management techniques in the prison setting. J Forensic Nurs. Apr-Jun 2013;9(2):111-9. doi: 10.1097/JFN.0b013e31827a5a89.

6. De Berardis D, Vellante F, Fornaro M, Anastasia A, Olivieri L, Rapini G, Serroni N, Orsolini L, Valchera A, Carano A, Tomasetti C. Alexithymia, suicide ideation, affective temperaments and homocysteine levels in drug naïve patients with post-traumatic stress disorder: an exploratory study in the everyday 'real world'clinical practice. Int J Psychiatry Clin Pract. 2020 Mar;24(1):83-7. doi: 10.1080/13651501.2019.1699575. Epub 2019 Dec 12.

7. De Berardis D, Marini S, Serroni N, Iasevoli F, Tomasetti C, de Bartolomeis A, Mazza M, Tempesta D, Valchera A, Fornaro M, Pompili M. Targeting the noradrenergic system in posttraumatic stress disorder: a systematic review and meta-analysis of prazosin trials. Curr Drug Targets. 2015;16(10):1094-106. doi: 10.2174/1389450116666150506114108.

8. Khosravi M. The mediating role of alexithymia in the association between attachment styles and borderline personality symptomatology. Health Psychol Res. 2020 Oct 1;8(2):8894. doi: 10.4081/hpr.2020.8894. eCollection 2020 Oct 5.

9. Fazel, S, Hayes, AJ, Bartellas, K, Clerici M, Trestman R. Mental health of prisoners: prevalence, adverse outcomes, and interventions. Lancet Psychiatry. 2016 Sep;3(9):871-81. doi: 10.1016/S2215-0366(16)30142-0. Epub 2016 Jul 14.

10. Goomany, A, Dickinson, T. The influence of prison climate on the mental health of adult prisoners: a literature review. J Psychiatr Ment Health Nurs. 2015 Aug;22(6):413-22. doi: 10.1111/jpm.12231. Epub 2015 Jun 30.

11. MacDonald, M. Women prisoners, mental health, violence and abuse. Int J Law Psychiatry. May-Aug 2013;36(3-4):293-303. 10.1016/j.ijlp.2013.04.014. Epub 2013 May 1.
12. Yalom, ID. The gift of therapy: An open letter to a new generation of therapists and their patients. New York: Harper Collins; 2001.

13. Bekhet, AK, Zauszniewski, JA, Nakhla, WE. Loneliness: a concept analysis. Nurs Forum. OctDec 2008;43(4):207-13. doi: 10.1111/j.17446198.2008.00114.x.

14. May, R, Yalom, ID. Existential psychotherapy. In: Corsini RJ, Wedding D, editors, Current psychotherapies. Belmont, CA: Brooks/Cole; 2005. p. 269-298.

15. Van Deurzen, E. Existential counselling \& psychotherapy in practice. 3rd ed. New York: SAGE Publications; 2012.

16. Van Deurzen E, Craig E, Lägle A, Schneider KJ, Tantam D, du Plock S. The Wiley handbook of existential therapy. Chichester, UK: John Wiley \& Sons Ltd; 2019.

17. Udo C, Melin-Johansson C, Danielson E. Existential issues among health care staff in surgical cancer care-discussions in supervision sessions. Eur J Oncol Nurs. 2011 Dec;15(5):447-53. doi: 10.1016/j.ejon.2010.11.010. Epub 2010 Dec 14.

18. Bohlmeijer ET, Lamers SM, Fledderus M. Flourishing in people with depressive symptomatology increases with acceptance and commitment therapy. Post-hoc analyses of a randomized controlled trial. Behav Res Ther. 2015 Feb;65:101-6. doi: 10.1016/j.brat.2014.12.014. Epub 2014 Dec 27.

19. Dindo L, Van Liew JR, Arch JJ. Acceptance and commitment therapy: a transdiagnostic behavioral intervention for mental health and medical conditions. Neurotherapeutics. 2017 Jul;14(3):546553. doi: 10.1007/s13311-017-0521-3.

20. Ducasse D, Fond G. Acceptance and commitment therapy. Encephale. 2015 Feb;41(1):1-9. doi: 10.1016/j.encep.2013.04.017. Epub 2013 Nov 18.

21. Forman EM, Herbert JD. New directions in cognitive behavior therapy: Acceptance-based therapies. In: O’Donohue W, Fisher JE, editors. General principles and empirically supported techniques of cognitive behavior therapy. Hoboken, NJ: Wiley; 2009. p. 102-114.

22. Russell DW. UCLA Loneliness Scale (Version 3): Reliability, validity, and factor structure. J Pers Assess. $\quad 1996 \quad$ Feb;66(1):20-40. doi: 10.1207/s15327752jpa6601_2.

23. Çağan Ö, Ünsal A. Depression and loneliness in disabled adults. Procedia-Social and Behavioral Sciences. 2014;114:754-60. doi: 10.1016/j.sbspro.2013.12.780.

24. Sodani M, Shogaeyan M, Neysi A. he effect of group logotherapy on loneliness in retired men. Research in Cognitive and Behavioral Sciences. 2012;2(1):43-54. (Persian)

25. Motamedin, M., Badri, R., Ebadi, G., Zamani, N. Standardization of Irrational Beliefs Test (4IBT-A) 
in Tabriz. Psychological Methods and Models. 2012;2(8):73-87. (Persian)

26. Tabachnick BG, Fidell LS. Using Multivariate Statistics. Boston: Allyn and Bacon; 2001.

27. Mahmoudpour A, Rayesh N, Ghanbarian E, Rezaee M. Effectiveness of acceptance and commitment therapy (ACT) on emotional regulation and loneliness of divorced women in Iran. J Marital Fam Ther. $2021 \quad$ Oct;47(4):831-842. doi: 10.1111/jmft.12492. Epub 2021 Mar 5.

28. Abosaidi Moghadam N, Sanagouye Moharer G, Shirazi M. Effectiveness of Acceptance and Commitment Therapy (ACT) on feelings of loneliness, shame, and guilt in female applicants for divorce. Journal of Applied Psychology. 2020;14(1):35-54. (Persian)

29. Javanbakht Z, Manshey G. The effectiveness of acceptance and commitment based treatment on meaning of life and feeling lonely of adolescents in the alternative care center. Quarterly journal of social work. 2017;5(4):39-42. (Persian)

30. Ghaffari Cherati AA. The Impact of Acceptance and Commitment Therapy on Social Acceptance and Loneliness of Women. Quarterly Journal of Family and Research. 2021 10;18(2):107-20. (Persian)

31. MirMoeini P, Bayazi MH, Khalatbari J. Comparing the effectiveness of Acceptance and Commitment Therapy with Compassion Focused Therapy on loneliness in patients with Multiple Sclerosis. Yafteh. 2021;22(4):132-45. (Persian)

32. Askari E, Tajeri B, Bermas H. Determining the Effectiveness of Acceptance and Commitment (ACT) Therapy on Interdependence, loneliness
Feeling and attribution style of the wives of addicts. Iranian journal of educational sociology. 2017;1(2):146-56. (Persian)

33. Hayes SC, Strosahl KD. A Practical Guide to Acceptance and Commitment Therapy. New York: Springer Science and Business, Media Inc; 2010.

34. Lashani L, Farhoudian A, Azkhosh M, Dolatshahee $\mathrm{B}$, Saadati H. Acceptance and commitment therapy in the satisfaction of veterans with spinal cord injuries spouses. Iranian Rehabilitation Journal. 2013;11(3):56-60. (Persian)

35. Hayes SC, Luoma JB, Bond FW, Masuda A, Lillis J. Acceptance and commitment therapy: Model, processes and outcomes. Behav Res Ther. 2006 Jan;44(1):1-25. doi: 10.1016/j.brat.2005.06.006.

36. Soroush A, Ziapour A, Abbas J, Jahanbin I, Andayeshgar B, Moradi F, Najafi S, Cheraghpouran E. Effects of Group Logotherapy Training on SelfEsteem, Communication Skills, and Impact of Event Scale-Revised (IES-R) in Older Adults. Ageing International. 2021:1-21. https://doi.org/10.1007/s12126-021-09458-2.

37. Jefferson A, Bortolotti L, Kuzmanovic B. What is unrealistic optimism?. Conscious Cogn. 2017 Apr;50:3-11. doi: 10.1016/j.concog.2016.10.005.

38. Hood Morris LE. A spiritual well-being model: Use with older women who experience depression. Issues Ment Health Nurs. Sep-Oct 1996;17(5):43955. doi: 10.3109/01612849609009412.

Submission: November 6, 2021 Revision received: November 8, 2021 Accepted for publication: November 8, 2021 